\title{
Correspondence
}

\section{NIH funding: agency rebuts critique}

We disagree with Joshua Nicholson and John Ioannidis'

claim that the peer-review system of the US National Institutes of Health (NIH) works against genuinely innovative research, because we believe that their analysis is flawed (Nature 492, 34-36; 2012).

They use 1,000 or more citations as a proxy for identifying breakthrough discoveries. However, more than $60 \%$ of the 158 highly cited articles they analyse cannot be categorized as innovative primary research: $34 \%$ are reviews, reports, clinical guidelines or descriptions of resources; $18 \%$ are clinical trials of the type primarily funded by industry; and $11 \%$ fall outside the NIH mandate that research should have the potential to improve human health (for our analysis, see http://dpcpsi.nih. gov/opa/natcorr).

Excluding these articles leaves 58 of the original 158: of these, $83 \%$ were funded by the NIH and $17 \%$ were funded by private industry.

The NIH welcomes further innovation in biomedical research, as evidenced by funding mechanisms such as the NIH Director's Pioneer, Transformative Research, Early Independence and New Innovator awards.

George Santangelo Office of Portfolio Analysis, National Institutes of Health, Bethesda, Maryland, USA.

george.santangelo@nih.gov David J. Lipman National Center for Biotechnology Information, National Institutes of Health, Bethesda, Maryland, USA.

\section{NIH funding: it does support innovators}

Joshua Nicholson and John Ioannidis conclude that "too many US authors of the most innovative and influential papers in the life sciences do not receive NIH funding", on the basis of their analysis of 200 papers sampled from 700 life-sciences papers with 1,000 or more citations (Nature 492, 34-36; 2012). However, my reanalysis of their data suggests that the US National Institutes of Health (NIH) has supported a substantial proportion of such contributions over the past 12 years.

For a random sample of 125 of the authors' pool of 700 highly cited papers, I found that 63 were reviews and 17 fell outside the life sciences. Of the remaining 45 original research papers, 34 (that is, $75 \%$ ) were supported by the NIH (source: NIH grants database and my own analysis); the other 11 papers did not receive NIH support for various reasons (for details, see go.nature. com/nywiid).

Nicholson and Ioannidis further underestimate the NIH's support for groundbreaking research by requiring both the first and last authors to be principal investigators on an NIH grant when, in fact, first authors are often graduate students. Steven L. Salzberg Johns Hopkins School of Medicine, Baltimore, Maryland, USA. salzberg@jhu.edu

\section{NIH funding: the critics respond}

In re-analysing our data (Nature 492, 34-36; 2012), George Santangelo with David Lipman, and Steven Salzberg each exclude two-thirds of the topcited US publications assigned by Scopus to life or health sciences. We consider that their analyses discard most health research that matters.

Clinical trials are primary research that catalyses preventive or therapeutic innovation; reports and guidelines also decisively inform and radically transform health. Extremely highly cited reviews formulate pioneering concepts or synthesize influential work.
Also, scholars reaching the top $0.01 \%$ with papers of any type predict some further excellence.

The authors' analyses depend on grant acknowledgments (75-83\% in both series) but these are a problematic metric because they represent grants that were awarded $10-15$ years ago when the NIH budget was expanding and acceptance rates were highest. Also, any of several co-authors can acknowledge a funding source if they are under pressure to demonstrate grant-related productivity, even if that source is irrelevant. And let's imagine a hypothetical funding system that forces all geniuses to quit science: $100 \%$ of papers could still acknowledge funding.

Groundbreaking projects account for less than $1 \%$ of awarded grants. Students whose papers reach 1,000 or more citations should certainly become principal investigators: stars will abandon systems that stifle independence.

John P. A. Ioannidis Stanford

Prevention Research Center,

Stanford, California, USA.

jioannid@stanford.edu

Joshua M. Nicholson Virginia

Tech, Blacksburg, Virginia, USA.

\section{Science alone cannot shape sustainability}

We agree that science can and should inform the sustainable development goals agreed at the Rio+20 conference (G. Glaser Nature 491, 35; 2012). But basing policy decisions on science alone may be unproductive.

Experience indicates that political receptiveness to scientific advice is essential for shaping policy. Climate-change policy-makers, for example, continually receive new technical and scientific input, but they still cannot agree how best to act on it to mitigate or adapt to climate change (J. Depledge Glob.

Environ. Polit. 6, 1-22; 2006).

Scientific evidence is rarely politically neutral or universally accepted; neither can it replace what is inherently a political process.

Suraje Dessai, Stavros Afionis, James Van Alstine University of Leeds, UK.

s.dessai@leeds.ac.uk

\section{Prize marks German journal centenary}

One hundred years ago today, the publisher Springer launched a German multidisciplinary journal named Naturwissenschaften ('natural sciences') at the behest of physicist and future editor Arnold Berliner. The journal was closely modelled on Nature.

Nature maintained its support for the journal throughout the political upheavals in twentiethcentury Europe. As a Jew, Berliner was forced to resign in 1935. Nature wrote: "We much regret to learn that on August $13 \mathrm{Dr}$. Arnold Berliner was removed from the editorship of Die Naturwissenschaften, obviously in consequence of non-Aryan policy" (Nature 136, 506; 1935). It also published a moving obituary when Berliner took his own life in 1942 (Nature 150, 284; 1942).

Naturwissenschaften -

The Science of Nature is now published exclusively in English. During this anniversary year, the journal will provide open access online to its most highly rated 100 articles, and will present the first Arnold Berliner Award for the best research article published in 2012, judged using Berliner's original motivations of excellence, originality and interdisciplinarity.

Joan Robinson Springer, Heidelberg, Germany. joan.robinson@springer.com

CONTRIBUTIONS

Correspondence may be sent to correspondence@ nature.com after consulting the guidelines at http:// go.nature.com/cmchno 